\title{
MUJERES MAPUCHE EN LA DIÁSPORA Y EL RETORNO AL WALLMAPU: ENTRE MICRO-RESISTENCIAS DE GÉNERO Y DESPOJOS COLONIALES
}

\author{
MAPUCHE WOMEN IN THE DIASPORA AND THE RETURN TO THE WALLMAPU: \\ BETWEEN COLONIAL SPOLIATION AND MICRO-RESISTANCE IDENTITY
}

\author{
Alicia Rain Rain ${ }^{1}$, Margot Pujal i Llombart ${ }^{2}$ y Enrico Mora Malo ${ }^{3}$
}

\begin{abstract}
La ocupación forzada del territorio histórico mapuche, Wallmapu, por la campaña militar chilena llamada Pacificación de La Araucanía, propició el desplazamiento forzado de personas mapuche hacia las ciudades. Desde una perspectiva analítica y política, en este artículo se analizan las experiencias de mujeres mapuche que se han desempeñado en el trabajo doméstico en la ciudad de Santiago de Chile, lugar de mayor asentamiento urbano de mujeres mapuche a nivel país. Se trata de un estudio etnográfico multisituado que contempla las regiones del Biobío, La Araucanía y Los Ríos, y la ciudad de Santiago. La perspectiva metodológica descolonizada y descolonizadora utilizada, involucró saberes y convenciones sociales propias mapuche. Las actoras fueron 32 mujeres mapuche que viven la diáspora y/o han retornado al Wallmapu. La estrategia metodológica incluyó observaciones participantes. Se entrevistó en profundidad a 20 mujeres. Se realizaron cuatro grupos de discusión en Santiago, y las regiones de La Araucanía y Los Ríos, que incluyó a 12 mujeres, más dos de las entrevistadas. Los hallazgos muestran continuidades coloniales en espacios laborales racializados, que se expresan en múltiples desgarros de clase, raza y género. Pero, de modo dialéctico hacen surgir subjetividades y micro-resistencias cotidianas que conforman identidades diaspóricas mapuche en las mujeres.
\end{abstract}

Palabras claves: continuidad colonial, trabajo doméstico, mujeres Mapuche, interseccionalidad, micro-resistencias mapuche.

The forced occupation of the Wallmapu, the Mapuche territory, though a military campaign known as Pacification of Araucania, contributed to the coerced migration of Mapuche people to the cities. This article delves, from an analytical and political perspective, into the experiences of Mapuche women who have worked in domestic service in Santiago de Chile, the capital city of the country with the highest number of Mapuche women. This is a multisited ethnographic research comprising the regions of El Biobio, La Araucanía, and Los Ríos, and the city of Santiago. The decolonized and decolonizing methodological perspectives used involved knowledge and social conventions characteristic of the Mapuche people. The methodological strategy included participating observation. Thirty two Mapuche women, who lived in the diaspora and have returned to the Wallmapu, participated. In-depth interviews were carried out with twenty women. Four discussion groups were conducted with 12 women, including two of the interviewed women, in the city of Santiago and in the regions of La Araucania and Los Rios. The findings show colonial continuities in racialized work spaces, which manifest themselves in a variety of class, race, and gender clashes, and which dialectically give rise to subjectivities and everyday micro-resistances that shape the Mapuche diaspora identity of these women.

Key words: Colonial continuity, domestic service, Mapuche women, intersectionality, Mapuche micro-resistances.

El pueblo mapuche, tras una larga resistencia al dominio español, mantuvo su autonomía y autodeterminación hasta inicios del siglo XIX. Luego, el Estado chileno, ya independiente de la Corona Española, entre el año 1869 y hasta 1883 por medio de la llamada Pacificación de La Araucanía lo despojó violentamente de su territorio y soberanía (Boccara 2007; Mallon 2009; Marimán 2006; Nahuelpan 2012; Zavala 2008). Este quiebre histórico propició un continuo colonial (Alvarado 2016). Se institucionalizaron prácticas de inferiorización y de represión (Caniuqueo 2009) aún vigentes en las políticas estatales integracionistas (Alarcón y Nahuelcheo 2008).

\footnotetext{
${ }^{1}$ Programa de Doctorado "Persona y Sociedad en el Mundo Contemporáneo", Departamento de Psicología Social, Facultad de Psicología, Universidad Autónoma de Barcelona. Barcelona, España. aliciarain@gmail.com

${ }^{2}$ Departamento de Psicología Social, Facultad de Psicología, Universidad Autónoma de Barcelona. Barcelona, España. margot.pujal@uab.cat

${ }^{3}$ Departamento de Sociología, Facultad de Ciencias Políticas y Sociología, Universidad Autónoma de Barcelona. Barcelona, España. enrico.mora@uab.cat
} 
Tras perder más del $90 \%$ de sus tierras, es un pueblo que sufre la diáspora (Ancán y Calfío 1998), que se agudiza en 1930 (Guerra 2014) y en los años 1950 y 1960 del siglo pasado (Abarca 2002). Estos desgarros tensionan y transforman la vivencia identitaria mapuche.

El pueblo mapuche, ahora precarizado (Hernández 2003) demandó devoluciones de tierras durante $\mathrm{La}$ Reforma Agraria (1964-1973), pero la Contra Reforma, en dictadura (1974-1980), implicó la pérdida de esos logros (Gündermann et al. 2009). Se fortalece la industrialización y el extractivismo en territorio mapuche, como paradigma desarrollista occidental que genera desigualdad, dominio y negación de los derechos colectivos de los pueblos originarios (Ríos y Solis 2009).

El pueblo mapuche actualmente representa el $79.8 \%$ del total de pueblos originarios en Chile (Instituto Nacional de Estadística [INE] 2017). Presenta un 30,8\% de pobreza frente a un 19,9\% de la población chilena (Ministerio de Desarrollo Social. Encuesta de Caracterización Socioeconómica [CASEN] 2015). Para algunos, Santiago -capital de Chile- simboliza mejoras materiales (Abarca 2002; Guerra 2014). El 88,4\% de personas pertenecientes a pueblos originarios que habitan zonas urbanas en la región Metropolitana son mapuche, y de ellas el 50,8\% son mujeres (División de Población. Comisión Económica para América Latina y el Caribe [CEPAL] 2017). Algunas de las razones han sido la posibilidad de realizar trabajos al mismo tiempo que cubren necesidades materiales (Bello 2002). Allí han coexistido la explotación laboral y discriminación, y a la vez la subsistencia material y resistencia (Alvarado 2016; Nahuelpan 2013).

La vida en la ciudad de Santiago, provocó el exilio exterior e interior, el desarraigo familiar y comunitario, y la negación sistémica y sistemática de la existencia de formas de vida del pueblo mapuche (Huenchuñir 2015). La asociatividad, la participación política, social y la apropiación de lugar (Alvarado 2017; Bello 2002; Curivil 2006; Imilan 2014; Sepúlveda y Zúniga 2015) han permitido resistir esta negación y reivindicar la identidad mapuche (Huenchuñir 2015). La identidad no como lugar fijo y estable, sino como proceso de identificación continua en movimiento (Hall 2003) y heterogéneo, dadas las relaciones de género y de generación (Díaz 2005).

La investigación se enfocó en las experiencias de mujeres mapuche que se desempeñan o se han desempeñado en el trabajo de casa particular. En primer lugar, porque tradicionalmente se ha subsumido la experiencia de las mujeres mapuche bajo la noción genérica de experiencia mapuche, analizada habitualmente a partir de la experiencia de los hombres mapuche a través de la categoría pueblo mapuche. Se trata de un sesgo androcéntrico que toma la experiencia de una parte, los hombres mapuche, como la experiencia de todo el pueblo mapuche. El efecto ha sido la desatención de la experiencia de las mujeres mapuche. En segundo lugar, nos fijamos en las mujeres mapuche que se han dedicado al trabajo doméstico, puesto que ha sido, como hemos señalado, uno de los principales empleos que las mujeres mapuche han desempeñado en la diáspora. Finalmente, el espacio del hogar es un espacio de producción y reproducción de las dinámicas y estructuras sociales de orden colonial, racial, clasista y patriarcal (Alvarado 2016; Cumes 2014; Millaleo 2011; Nahuelpan 2013) que nos permite identificar con mayor claridad la interseccionalidad de las dimensiones de la desigualdad social que afecta a las mujeres mapuche en la diáspora.

Tras el despojo, la reivindicación identitaria mapuche fue castigada (Caniuqueo 2009; Guerra 2014; Huenchuñir 2015). Desde 1980 afloran los procesos asociativos en la ciudad de Santiago (Alvarado 2017; Bello 2002; Imilan 2014), pero los liderazgos femeninos mapuche no han sido visibilizados (Levil 2015). En 1990 surge la Corporación de Desarrollo Indígena (CONADI) que permite la focalización de demandas mapuche (Bello 2002). También, proliferan las demandas por la recuperación del territorio mapuche, y revitalización de formas y prácticas propias (Bello 2002; Imilan 2014). Desde 1997 en adelante, autores mapuche proponen un retorno mapuche de carácter político, en un horizonte de autonomía territorial y autoderminación en tanto nación. Pero se trata de un sentido de nación comunitario no vinculado a la noción de estado moderno occidental (Rojo et al. 2003) debido a la persistencia de los valores, prácticas y sistemas de creencias mapuche, a pesar de la hegemonía del escenario occidental (Alarcón y Nahuelcheo 2008), pero que tampoco son ajenos a los procesos de transformación.

El lugar social inferiorizado de las mujeres de pueblos originarios (Calfío 2012; Stolcke 1993) recibe escasa atención académica (Montecino 1984), social y política (Espinosa 2009). La ocupación de las mujeres mapuche como trabajadoras de casa particular en la ciudad de Santiago, las invisibilizó y vació de valor social (Bello 2002; Montecino 1984). Surge así la necesidad de visibilizar tanto sus sujeciones como sus resistencias y agencias (Hirsch 2008), desde la perspectiva de género interseccional, fijándonos específicamente en las opresiones simultáneas por razones de raza, clase y género (Espinosa 2009; Stolcke 1993). Entonces, nos preguntamos, ¿cuáles son las principales características de las experiencias de subalternidad en las mujeres que viven la diáspora mapuche en la ciudad de Santiago, y en las que han retornado al Wallmapu ${ }^{1}$ ? Así, el objeto de análisis son las experiencias de las mujeres mapuche en 
la diáspora, su devenir en el trabajo doméstico y en las cadenas de cuidado (Mora y León 2011).

Enmarcamos nuestro trabajo en los estudios de la diáspora mapuche y no en los estudios sobre migraciones de poblaciones racializadas porque interesa reconocer los procesos históricos de despojo territorial y político, expropiación de tierras, empobrecimiento estructural desde el Estado chileno y afectaciones identitarias en hombres y mujeres del pueblo mapuche.

Las interseccionalidades de mujeres de pueblos originarios y afrodescendientes (Calfío 2012; Cumes 2009; Espinosa 2009; Segato 2018) nos llevan a adoptar la perspectiva de género interseccional, que es para muchas autoras la mayor contribución del feminismo al análisis social (McCall 2005; Yuval-Davis 2006, 2017) y se ha convertido en un espacio analítico primordial para enfrentar conflictos en torno a la diversidad y dar cuenta de la formación compleja de las diferentes posiciones de sujeto, al cuestionar lecturas monovectoriales y los procesos de configuración categorial con un lenguaje que va más allá de las políticas de la identidad (Cho et al. 2013). Su enfoque va dirigido a trabajar con los efectos conjuntos de los procesos de subordinación -simultaneidad de opresiones (Combahee River Collective 2012 [1977])- o la necesidad de atender a las interrelaciones de género, etnicidad y clase en los análisis feministas dando lugar a una concepción heterogénea y situada de las identidades de género mapuche.

Las mujeres racializadas, desde el año 1960 en América Latina, han denunciado las imbricaciones de dominación (Curiel 2007) y su escasa referencia académica sobre la producción de conocimiento, obedece a una subalternización que no solo se desprende del androcentrismo académico, social y político, sino del colonialismo, que incluso afecta a las feministas decoloniales (Curiel 2007; Rivera 2010). De allí la invisibilización histórica de las agencias de las mujeres mapuche en la historia de resistencias (Calfío 2019) incluyendo a las organizaciones políticas mapuche (Levil 2015). Así, precisamos analizar la construcción de conocimientos y prácticas de resistencia desde la memoria histórica colectiva, a través de la vida cotidiana en la diáspora (Rivera 2010).

\section{Método}

La metodología ha sido cualitativa, y nuestra orientación es la epistemología mapuche, con miras a la descolonización como ejercicio de autodeterminación en contexto (Tuhiwai 2016 [1999]). Nos centramos en la particularidad del pueblo mapuche, de una forma situada y local, y con una perspectiva metodológica descolonizante que considera sus saberes y convenciones sociales propias para establecer relaciones sociales, en este caso, en el proceso investigativo (Tuhiwai 2016 [1999]).

Nuestro estudio fue de tipo etnográfico multisituado (Clifford 1999). Realizamos el trabajo de campo entre los meses de noviembre de 2017 y abril de 2018, con mujeres mapuche de la diáspora en la ciudad de Santiago, y las retornadas al Wallmapu, particularmente en las regiones del Biobío, La Araucanía y Los Ríos (Chile). Los criterios para la selección de actoras fue: mujeres que se identificaran como mapuche, de 18 años, y más (consideradas adultas de acuerdo a la legislación chilena actual) y que vivan o hayan vivido en la ciudad de Santiago por medio año o más. De un total de 32 mujeres, 20 de ellas participaron de las entrevistas en profundidad y observación participante; en tanto que otras 12 mujeres, a las que se agregaron dos de las entrevistadas, participaron en cuatro grupos de discusión (compuestos por tres o cuatro mujeres) respecto a los sentidos asociados a la diáspora y el retorno.

Las actoras de este estudio presentan diferentes trayectorias vitales. Las mayores de 70 años vivieron las experiencias diaspóricas en las primeras décadas posteriores al despojo, donde las precarias condiciones materiales las obligaron a concentrar sus esfuerzos en lograr la supervivencia material familiar, de otras personas mapuche y la propia. Luego, las que tienen más de 60 años vivieron su juventud en la época de dictadura militar chilena, que implicó la pérdida de reivindicaciones de tierras durante la Reforma Agraria. Allí, el pueblo mapuche, al igual que la sociedad chilena, vivió procesos de graves vulneraciones de derechos humanos. Las mujeres nacidas a fines del siglo XX afrontan exclusiones sociales más sutiles, pero viven las desigualdades dentro de la sociedad chilena junto a una mayor heterogeneidad de movimientos reivindicativos políticos e identitarios mapuche.

Nuestra entrada al campo, acercamiento y contacto con las mujeres fue diversa. La técnica que utilizamos fue la de bola de nieve. Seguimos las orientaciones éticas del código de buenas prácticas de la Universidad Autónoma de Barcelona $^{2}$ e hicimos uso del consentimiento informado. Siguiendo principios de metodologías descolonizantes, el cuidado y el uso de convenciones sociales propias del pueblo mapuche ${ }^{3}$ fueron una constante en el trabajo de campo, tales como el pentukün ${ }^{4}$, que involucra establecer conversaciones para crear confianzas, conocerse desde las raíces familiares, $\mathrm{küpal}^{5}$, y características geográficas, tüwü̈ ${ }^{6}$, así como construir una relación en el contexto de la investigación, acordes a los tiempos de las personas y sus $l o f^{7}$. Algunas de las mujeres que contactamos en el proceso de investigación no accedieron al estudio por manifestar cierto sentir de cosificación, tras experiencias previas de frecuente extractivismo académico colonial.

A través de la observación participante, realizamos acompañamientos cotidianos a algunas de las mujeres 
en sus trabajos y en sus hogares, para comprender tramas, experiencias y relaciones. Llevamos a cabo entrevistas en profundidad y propiciamos sesiones grupales con el fin de contar con expresiones vertidas en un contexto colectivo.

Para la recogida y el análisis de los datos, seguimos el siguiente proceso: durante el trabajo de campo íbamos escuchando las entrevistas y discusiones colectivas, a la vez que elaborábamos el diario de campo. Las entrevistas y discusiones colectivas fueron grabadas con consentimiento informado y libre de las participantes bajo la condición de anonimato y confidencialidad, que consta en las grabaciones de las entrevistas ${ }^{8}$. A medida que avanzaba el trabajo de campo, íbamos realizando escuchas o lecturas sucesivas de la información con el fin de alcanzar el criterio de saturación de la información. Las grabaciones de las entrevistas, los grupos de discusión y las notas de campo, una vez transcritas, las analizamos a través de la técnica cualitativa del análisis de contenido, para el que nos servimos en un primer momento del software de análisis cualitativo Atlas-ti para generar codificaciones del material y alcanzar unidades interpretativas acotadas. En palabras de Braun y Clarke (2008), el análisis de contenido de corte cualitativo consiste en identificar, analizar e informar patrones dentro de los datos, agrupando y organizando los mismos en diferentes categorías temáticas. Este análisis categorial nos permitió aprehender la experiencia biográfica de las mujeres entrevistadas, así como la interpretación de lo expresado con base en un contexto histórico e ideológico con el que dotar las prácticas y discursos de un sentido social. El objetivo del análisis fue profundizar en su contenido explícito y latente, y relacionarlo con el marco teórico adoptado, la perspectiva de género interseccional y el contexto social situado e histórico específico (Cáceres 2003). En este sentido, el análisis alcanzó un nivel interpretativo que permitió contextualizar el contenido dentro de un entramado de relaciones de poder colonial, clasista y patriarcal.

\section{Resultados}

Los resultados se organizaron en tres grandes categorías construidas en relación con la perspectiva interseccional, con el contexto sociohistórico y situado específico, y con el objetivo planteado. Teniendo en cuenta que las experiencias de las actoras están mediatizadas por el uso de las categorías lingüísticas disponibles, se nombraron categorías retomando la terminología propia de la lengua mapuche ${ }^{9}$.

La primera categoría se denominó 'Motivos, desgarros y movimientos en la experiencia diaspórica', y está relacionada con la experiencia propiamente diaspórica, es decir con el viaje de Wallmapu a Santiago y de Santiago al Wallmapu. A través de ella se presentan tres subcategorías: cuidados, emociones y elaboración de duelos; voluntad de colonizar la corporalidad femenina mapuche; y consciencia en torno a las violencias de la exclusión.

La segunda categoría, 'Mapuche kimün ${ }^{10}$ y nütram ${ }^{11}$ en la diáspora y el retorno al Wallmapu, se refiere a la formación del "che" ${ }^{12} \mathrm{o}$ de la persona en el seno familiar y del 'lof' y su conservación a pesar y a través de la diáspora. En esta categoría se ubican dos subcategorías: creencias, prácticas mapuche y kimün; y el Nütram: memoria colectiva y atribución de autoridad, consejos de vida otorgado por personas mayores y sabiduría mapuche, o con experiencia sobre determinados asuntos.

En la tercera categoría que denominamos 'Otras resistencias mapuche cotidianas en el tránsito' aparecen otras estrategias de agenciamiento y resistencia de las mujeres. Se compone de tres subcategorías: soledad, sororidad y búsqueda activa de reconocimiento; autonomía económica y apoyo familiar; revitalización identitaria y lingüística mapuche en la ciudad y el Wallmapu. En el apartado que sigue, damos cuenta del desarrollo de dichas categorías.

\section{Motivos, desgarros y movimientos de la experiencia diaspórica}

El despojo propiciado por el Estado de Chile a fines del siglo XIX y principios del XX, que por medio de la acción militar y civil usurpó el territorio mapuche, despojó al pueblo mapuche de las condiciones para el comercio ganadero, producción ganadera y oficios en la platería, entre otros (Nahuelpan 2012). Esto forzó los desplazamientos masivos de las mujeres a las grandes ciudades, en condiciones de subalternidad dentro de un contexto colonial persistente que generó desgarros cotidianos.

\section{Cuidados, emociones y elaboración de duelos}

Los desplazamientos a la ciudad de Santiago se hicieron con miras a cuidar de otras personas, sus padres y hermanas menores. Mariela (23 años, Región del Bíobio) se movilizó para los cuidados de sus hermanos:

Y yo después trabajé, trabajé un año ahí, después ya empecé como '¿cómo hago pa' generar más plata para mis papás?', para ayudarles, para poder que ellos no anden llorando, pasando hambre, diciendo 'pucha, no tengo qué darles'. Por mis hermanos, yo más veía por mis hermanos, yo decía 'pero mis hermanos no tienen que sufrir, no, como yo.

El trabajo de casa particular fue la principal forma de empleo que muchas mujeres mapuche encontraron 
en Santiago, debido especialmente a las condiciones dependientes en lo económico, desiguales y abusivas (Nahuelpan 2012) que encontraron en su llegada. Nos dice Elizabeth de 40 años (Santiago): "Como no tenía donde vivir, la opción era puertas adentro. Entonces te daban cama, comida, trabajo y el sueldo, dije iya!, y me quedé trabajando ahî".

El viaje implicó también una dimensión emocional intensa, especialmente el duelo por un mundo que se dejaba atrás para enfrentarse a un nuevo contexto amenazante y difícil de prever. Josefina de 28 años (Región de La Araucanía) corporalizó el cambio:

Cuando llegamos, ¡eh!, para mí fue a nivel corpóreo, a nivel simbólico, a nivel de todo, fue un cambio, ¡ eh! sumamente doloroso, porque era enfrentarte a un contexto de pasado, de ruralidad, de no conocer mucho de ciudad, a un contexto totalmente dinámico y muy castigador, una dinámica muy rápida.

La elaboración emocional de las pérdidas que implica el viaje y el asentamiento en una ciudad, llevó a transferir los afectos truncados a las personas que se cuidan en las casas que sirven, especialmente a las niñas y niños pequeños. Mariela (23 años, Región del Bíobio), recuerda su vínculo con el nieto de sus empleadores:

Y me acuerdo que esos tiempos, él después se fue como apegando porque sus papás de él igual eran como separados y era chiquitito, lo iban a dejar con su abuela y me decían que yo lo viera poh! ¡Yo lo veía y después se apegó a mí poh!, le daba la mamadera cuando llegaba, en brazo mío y era como que me refugié en él, porque como que no veía a mi hermanita, ¡era como él poh!.

Es decir, la diáspora significó entrar en las cadenas del cuidado, parafraseando el conocido concepto de cadenas transnacionales del cuidado (Mora y León 2011), para aquí referirnos al efecto colonizador del Estado de Chile en el pueblo mapuche, generando flujos extractivos del cuidado y del servicio hacia las familias urbanas chilenas.

\section{Voluntad de colonizar la corporalidad femenina mapuche}

El trabajo doméstico subalternizado es un espacio invisible a nivel social y político, con lo cual, las posibilidades de vivir diversas opresiones son frecuentes, más en una ciudad desconocida y con códigos diferentes al de un lof. La presencia y acompañamiento familiar se vuelve central frente a la indefensión. Mariela de 23 años, desde su lof (Región del Bíobio) recuerda su experiencia:

Ya me fui, mi prima me fue a buscar al terminal con, con mi jefa que iba a ser, pero igual ipo!, lloraba. Después cuando ya de primera así, a ella la vi, ipucha! ¡me sentí feliz! porque tenía una prima, tenía como algo, ¡un respaldo ahí poh!, como que ya si me pasaba algo, ya estaba mi prima.

Estos trabajos se fijan como lugar para las mujeres mapuche en la época de la conquista española, y luego re-actualizado en el colonialismo chileno a través de las relaciones coloniales cotidianas. Francisca, de 85 años (Región de La Araucanía), recuerda sus primeros pasos en los fundos aledaños a su lof:

¡Me querían!;me querían!;para qué decir! jtrabajaba como animal poh! [ríe]. ¡Uno no para!, por eso uno se acostumbra a trabajar así, porque a uno la tienen así, ¡no hay horario!, ¡no hay descanso! Después de que hacía todo, estaba dentro de la cocina y me decían ¡hace esto!, ¡hace esto otro!, ¡uno no para!.

Francisca señala algo característico de las formas de disciplinamiento colonial ejercido por las y los 'patrones'. El uso de los afectos, 'ime querían!', nos permite apreciar como las estrategias afectivas se solapan como un acto de apropiación del cuerpo de las mujeres mapuche. De ese modo la empresa colonial hace posible una productividad mayor, pero también construye vínculos de dependencia y subordinación mediante una política emocional fundada en el sometimiento de expresar amor a quien no se quiere.

La subordinación de las mujeres mapuche se puede comprender como un lugar fijado en el servicio doméstico, vigilado y controlado por las mujeres winka, 'las patronas'. Marcelina (66 años, Región de Los Ríos), vivió con impotencia la interrupción de su formación secundaria, aún con apoyo de su empleador, 'el patrón':

"Entonces, el hombre ese, le decía a la señora 'pero si la Marcelina quiere salir adelante, ¿por qué tú no le das esa oportunidad?', le decía, y yo a veces lo escuchaba '¡no!', - le decía ella, 'porque ella va a trabajar no más, y yo aquí, no necesito persona educada', yo quiero como ella no más. Así, para que trabaje no más en mi casa, porque tiene que lavar la loza, y hacer aseo no más ¿y a qué hora va a ir a estudiar? Y en la noche tiene que ver a los niños.

\section{Conciencia en torno a las violencias de la exclusión}

Esta política emocional para sustentar las prácticas de género coloniales de gestión del trabajo doméstico por 
parte de las/los empleadores se apoya en un dispositivo forjado en prejuicios, estereotipos y discriminaciones que las personas mapuche padecen desde la infancia, especialmente en los contextos urbanos. Así lo expresa Yolanda de 38 años (Región del Bíobio): "Era una zona que el mayor porcentaje son niños mapuche poh!, la mayoría casi, y algunos que eran ¡claro que sí!, que algunos les daba vergüenza ¡sí! Esos eran más tímidos, sus personalidades, más que otras".

Sayen de 37 años (Santiago), también vivió estas opresiones: "En el colegio, en el curso que yo tenía, entonces era más fácil, pero ¡siempre!, ya una pelea pequeña ¡ah, que el indio! ¡que él acá! Entonces ¡siempre! ¡ya el mapuche!”.

Josefina de 28 años (Región de La Araucanía), en su experiencia en la ciudad de Santiago, recuerda:

Cuando estábamos en clases, nos agredían físicamente, nos molestaban. Y éramos las dos, como que siempre estábamos súper juntas frente a esta situación. Yo era como un, un poco más, como se dice 'parada en la hilacha' [confrontacional], pero mi...mi compañera, me acuerdo de ella ¡sufrió mucho!, porque le escondían los zapatos. Era un tema de...de agresión física constante.

O la exclusión, como recuerda Amalia de 66 años (Santiago): "Mire, en ese tiempo, más de diez años, más de 12 años no tenía. Se juntaban en la puerta, conversaban, decían 'oye entremos a mi casa, pero ¡tú no!' (emotividad). 'Yo me sentía ¡muy mal! ¡muy mal!’.

Las experiencias de subordinación se mantienen en el tiempo, repitiéndose hasta las generaciones más reciente de mujeres mapuche en la ciudad de Santiago. Además se trata de prejuicios androcéntricos que invisibilizan a las propias mujeres como sujetas políticas, Valeria de 23 años (Santiago), nos comenta: "Acá en Santiago, nos tratan como ¡los indios, los winkas ${ }^{13}$, los ...! Muchos aquí nos ponen apodos, como le conté la vez anterior, aquí ya nos pusieron apodos, que somos ¡las quema neumáticos!”.

La vinculación de mujeres mapuche con actos de terrorismo aflora en los imaginarios de la población chilena, debido a los discursos políticos, sociales y periodísticos, que, en forma estereotipada e interesada políticamente, abordan el conflicto entre el Estado y el pueblo mapuche en términos de represión.

\section{'Mapuche kimün y nütram': en la diáspora y el retorno al Wallmapu}

El kimün, conocimiento mapuche, comprende un saber, principalmente de personas mayores, ancianas o personas que han tenido una experiencia sobre la cual otras pueden aprender. Este kimün está asociado a las prácticas culturales cotidianas, participación en ceremonias, conocimiento y uso de la lengua mapuche, mapudungun ${ }^{14}$. Dada la experiencia con instituciones eurocéntricas sobre las que se ha forjado el devenir del pueblo mapuche, este kimün toma como préstamos los conocimientos occidentales y dialoga desde sus saberes propios para construir una forma particular de comprensión del mundo.

\section{Creencias, prácticas mapuche y kimün}

Ser parte del pueblo mapuche se logra por medio de sistemas de creencias y prácticas propias, lo cual genera un sentido de pertenencia y de seguridad, lo que contrasta con las experiencias de soledad, explotación laboral y discriminación que las mujeres afrontan en la ciudad. Fernanda ${ }^{15}$, de 63 años (Región de Los Ríos), rememora un ngillatün ${ }^{16}$, en uno de los tantos viajes que hizo desde la ciudad de Santiago a su lof, y desde allí una forma diferente de estar y sentirse parte de estas ceremonias propias de su pueblo:

\section{Me dícuenta de que estaba llorando, no me podía controlar, me corrían las lágrimas, buen rato no paraba de llorar. Después que dejé de eso, me corrían las lágrimas, eso fue harto, dije yo ' $j o h$ !, esto sí que es más poderoso que cualquier cosa, porque aquí parece que de verdad está Dios.}

Vivenciar las prácticas culturales aporta a la construcción del kimün, conocimiento. El consumo de alcohol, la violencia intrafamiliar, entre otros malestares, fruto de la situación de vulnerabilización de la diáspora entre otras, también han llevado a la necesidad de buscar apoyos en instituciones externas, como por ejemplo la Iglesia. Yolanda (38 años, Región del Bíobio) explica:

Entonces muchas familias optaron por ir a la Iglesia y no seguir con su cultura, dejaron de lado su lengua, hasta la ropa ; todo! Se fue disminuyendo. Igual a algunos lamuen $^{17}$, les gustaba un poco el trago, entonces algunas mujeres para evitar eso, para evitar eso como los malos tratos hacia la mujer, porque uno sabe que con el trago, las personas se ponen violentas, $\mathrm{y}$ la mayoría de las familias optaron por eso de participar en las iglesias, para que, como para que las familias dejen de lado todo eso.

Un aspecto fundamental del sistema de conocimiento, kimün, es que implica un conjunto de creencias y prácticas mapuche que contrasta con las experiencias que viven en la ciudad y que desde ese lugar rememoran. María, de 32 años de edad (Santiago), nos muestra el contraste de su infancia en el lof, vinculada a la vida comunitaria y a los vínculos de 
solidaridad en el trabajo de apoyo mutuo en la agricultura, la ganadería, o la pesca, entre otras, que constituye una de las dimensiones prácticas del kimün, donde el conocimiento se produce en una práctica colectiva comunal: "Era una vida bastante tranquila en cuanto a, socialmente hablando, con los vecinos, con la familia, constantemente visitándose, ayudándose. ¡No sé!, recuerdo mucho los mingakos ${ }^{18}$. Y así, eso recuerdo de mi niñez".

Sayen, de 37 años (Santiago), proveniente de un lof en la Región de Los Ríos, dice respecto a los mingakos: "Yo lo que recuerdo que cuando nuestro papá sembraba, tenía su siembra de trigo, papa. Entre los vecinos era una ayuda mutua. ¡o sea! si esta vez, mi papá necesitaba gente para trabajar, la gente iba, y se juntaban todos ahí, y salía toda la siembra, y así viceversa, después se iba al otro lugar".

La forma de vivir la cotidianeidad en un lof implica seguir ciertas normas, las cuales responden a una estrecha relación de los seres humanos y la naturaleza. Al respecto, Fernanda de 63 años, en la Región de Los Ríos, recuerda: "Eso era casi imperdonable. Era culpa de la mamá y del papá si el sol llegaba y el niño estaba acostado, porque traía malas vibras que el sol lo pillara a uno durmiendo".

Carolina de 48 años (Región de Los Ríos), quien ha retornado a su lof, cuenta su experiencia por la imposibilidad de participar de los ngillatün, que en el suyo denominan trawün: las transgresiones forman parte de la preocupación de las mujeres.

Una o dos veces, cuando estaba en Santiago, no pude participar en el trawün $^{19}$, cuando estaba en el desagüe Riñiwe ahí ayudé a mis papás, pero ayudaba no más, pero qué pasó, ¡casi morí!, me llegó casi un castigo. Después tuve que machitucarme ${ }^{20}$, tuve que machitucarme dos veces. Por el trabajo, me va a dar un castigo de Dios, porque como yo trabajaba, no podía participar, cuando estaba mi mamá, le solía ayudar, pero ¡no! Tuve que entrar en el trawün, ahí se me pasó.

La forma de habitar los espacios y la conexión con espíritus protectores, los ngen $^{21}$, forma parte de las creencias entre las familias mapuche, lo que Marcelina de 66 años (Región de La Araucanía) recuerda:

Entonces mi papá vivió más allá, no aquí, vivió en un alto, porque mi abuelo decía, 'que nosotros los mapuche, teníamos que estar siempre en una altura, porque de ahí, nuestro chaw ngenechen ${ }^{22}$, los miraba, y los guiaba'. Entonces, siempre había que hacer así, en un alto, su casa. Y así, obedecieron ellos, mi papá”.

\section{Nütram, memoria colectiva y atribución de autoridad}

Antes del viaje de las mujeres, las madres y los padres dieron paso a una serie de recomendaciones y consejos, que comprenden el nütram, el cual se caracteriza por la memoria colectiva del pueblo mapuche y las diversas formas de resistencia que han construido a lo largo de su historia de lucha anticolonial. Este operó para el asentamiento en la ciudad de Santiago, y también en lo relativo a la adecuación a las normas de las familias mapuche que cuidaron de ellas, antes y durante sus primeras experiencias laborales. Así, Marisol de 69 años (Santiago), rememora:

Mi mamá, lo único que me acuerdo que les dijo 'me lo cuidan mucho', entonces él le contesta 'pero dígale usted que nos haga caso, que le haga caso a su madrina', porque venía a ser mi madrina, mi prima. Eso me acuerdo de que le dijo a mi mamá, y ella me dice 'sí, le tiene que hacer caso a su madrina ; todo lo que ella le diga!'.

El respeto a los padres formó parte de la enseñanza de algunas de las mujeres entrevistadas, y el nütram para su cuidado en la ciudad. Marcelina, de 66 años (Región de La Araucanía), explica:

Y me vine yo, a pedirle el permiso a mi papá, y él me autorizó, y me dijo ‘ ¡muy bien hija!, usted así, siempre tiene que hacerlo, respetar a los padres. Todo eso pienso, tu mamá, y usted todo eso, usted tiene que cuidarse en esa ciudad', -me decía-, 'te pueden pasar muchas cosas, no salga a ningún lado con nadie, es muy peligroso, y nosotros vamos a sufrir mucho, si a usted, te pasa algo, por ahí’ ¡ ¡Ya! Y eso lo llevé grabado, y me fui.

\section{Otras resistencias mapuche cotidianas en el tránsito}

Las mujeres mapuches han desplegado una pluralidad de resistencias nómadas a través de la sororidad y la búsqueda activa de reconocimiento, la autonomía económica y el apoyo familiar, y, finalmente, la revitalización identitaria y lingüística mapuche en la ciudad y el Wallmapu.

\section{Soledad, sororidad y búsqueda activa de reconocimiento}

En las primeras décadas del despojo colonial mapuche en Chile, el empobrecimiento masivo mapuche hizo que muchas mujeres vieran en la ciudad de Santiago una oportunidad de sobrevivencia. Así, Rosita (92 años, Santiago), hizo el viaje, siendo una niña de no más de 11 años, ya hace poco más de ochenta años atrás:

¡Ya! después empecé a ser mayor, y dije ‘iya!, me gustaría irme a Santiago. Sin conocer. Y 
me dice una señora ya de edad, evangélica 'ándate conmigo, yo te voy a acompañar para que te vaya bien'. No me acompañó na', me acompañé yo sola. Me gustó ser independiente.

El empobrecimiento no cesó en la ciudad, y la soledad acompañó a las diásporas mapuche. Sin embargo, como recuerda María, de 32 años (Santiago), la víspera del nacimiento de su hija mayor y el apoyo de una mujer mapuche en la ciudad de Santiago, revitalizando el principio de hermandad mapuche, solidaridad mapuche, reymagnen ${ }^{23}$, en contexto urbano: "Y como no conocía a nadie, y tampoco volví después a hablar con mi tía, con el caballero que estaba ahí. Entonces fue ¡súper doloroso! Y así es que ella me dijo-, 'sabís que mi guagua dejó harta ropa, así es que yo te la voy a dar a ti, para que tengas para tu bebé"”.

El orgullo mapuche constituye un acto de resistencia frente al integracionismo y la opresión, exigiendo un trato digno de quien las contrata, como señala Elizabeth, de 40 años (Santiago): "Yo creo que el hecho del orgullo de ser mapuche hace que uno no se rebaje ante el resto, entonces las personas, mis jefes, me trataban de tú a tú, de repente me decían "qué vas a estar comiendo en la cocina, ven a comer acá', siempre me relacioné así y con la gente alrededor también".

Por medio del nütram -consejo de vida y transmisión de valores mapuche desde las personas mayores-, a Paulina de 45 años (Santiago), su padre les decía a ella y sus hermanos, antes de emprender el viaje a Santiago:

Siempre nos decía: 'ustedes ¡nunca!, pero ¡nunca! se avergüencen de su apellido, ¡nunca lo hagan! Siempre ustedes con la frente en alto, ustedes pueden trabajar en la calle, ¡no sé!, pueden trabajar tanto en casa como en una oficina, pero siempre sean las mismas personas. Y no discriminen a nadie'.

Este consejo paterno señala la importancia de identificarse como mapuche como un rasgo valioso, que configura sus ideales. Pero señala algo más, casi sugiriendo un empoderamiento de aquello que el entorno chileno degrada, para evitar la violencia simbólica de quien ocupa una posición subalterna participando de los prejuicios y estereotipos que la población chilena ejerce sobre el pueblo mapuche. Una forma de apropiación se presenta también en el retorno al Wallmapu-desde la diásporaque implica para muchas, la revitalización de sus prácticas mapuche. Carolina de 48 años (Región de Los Ríos) en su participación en los ngillatün señala:

¡Sabe, que yo no me pierdo!, porque cuando ya explican, me voy al tiro adelantando en todo [las indicaciones en la ceremonia se dan en lengua mapuche], ya están diciendo que el muchai $^{24}$ hay que dejarlo adelante, en mapudungun. Total, que hay que pasarlo a dejar ahí adelante en el $\tilde{n} g o l^{25}$ ¡ahí lo están diciendo todo!

Enseñar a otras personas sobre las creencias y prácticas mapuche son oportunidades para la reivindicación identitaria. María (32 años, Santiago), rememora su trayecto como asesora intercultural en salud, luego de ser trabajadora de casa particular:

A los funcionarios de salud, y les dije ‘¿cómo van a traer una machi?', -y les pregunté-, ‘tienen dónde recibirla? ¿Y dónde va a ser su atención? ¿tienen zugu machife ${ }^{26 ? ' . ~}$ Entonces empecé a hablar de algo que ellos no entendían, y eso como que les generó algo así, como mucha ¡no sé!, como que les dio, les hizo mucho sentido lo que yo les decía, y ahí pasé a cumplir un rol.

\section{Autonomía económica y apoyo familiar}

$\mathrm{El}$ acceso de las mujeres mapuche a empleos en las ciudades tiene un efecto dialéctico. Por un lado, favorece una subjetividad de colonización y contribuye a la subordinación, pero también contribuye al establecimiento de una subjetividad de mujer trabajadora, que da paso al agenciamiento y empoderamiento por medio del acceso a la remuneración. Así lo expresa Amalia de 66 años (Santiago):

Con mi mama ¡era terrible! Sentíamos que venía, guardábamos la ropa, en caso de salir. Uno como niña ¡no sabe qué hacer! Entonces, por eso yo, le agradezco a mi mamá 'libre al viento', no depender de nadie. ¡Eso sí! los vecinos fueron muy buenos, pero de ahí tampoco.

La independencia económica impulsó a Amalia a realizar labores remuneradas a temprana edad, similar a la trayectoria de su madre Rosita de 92 años (Santiago): "Ya después llegué a 11 años y empecé yo ¡me gustó! 'porqué las otras ganaban y yo no'. Entonces yo también, dije yo 'yo también voy a trabajar'. Empecé a trabajar ganando 200 pesos mensuales".

El trabajo remunerado le otorgó a Rosita y Amalia autonomía económica y sobrevivencia material en la ciudad de Santiago. La vida laboral también transformó las subjetividades. Sayen, de 37 años (Santiago), observó esto en su madre: "Entonces, eso también le ayudó a ella a poder salir adelante y a enfrentarse a 
otras personas, de a poco, que también es bueno para la mujer, porque la mujer era como siempre más tímida, la mujer mapuche, en general. Yo igual me considero, quizá ahora, he ido perdiendo la timidez".

El trabajo de casa particular generó un nuevo conocimiento, un proyecto personal de cocina gourmet mapuche en el retorno de Yolanda (38 años, Región del Bíobio), como transformación cultural: "Entonces eso fue lo que más rescato, el tema de la cocina, porque uno aprendió a conocer ingredientes nuevos, diferentes tipos de comida. ¡Entonces si uno quiere trabajar en temas de turismo gastronómico, uno puede complementar lo que aprendió allá y con lo que tiene acá poh!’.

Las múltiples experiencias de explotación laboral de las mujeres han potenciado las resistencias, tal como relata Mariela (23 años, Región del Bíobio), afirmando su propio proyecto vital: "Yo les dije un día, la niñita ya estaba grande ¡ya! La niñita tenía casi los dos añitos. Yo le dije 'yo me voy a salir', porque igual era mucho. Mi jefa no quería, no quería, me exigía más plata, me, pero yo le dije que ¡no!, porque yo igual era mucho lo que trabajaba".

La sujeción del agenciamiento de las mujeres mapuche se presentó principalmente en el inicio del desempeño laboral en la ciudad de Santiago, pero tras la experiencia de opresión por raza, clase y género, ellas exigen sus derechos como trabajadoras. Estos derechos a menudo invisibilizados por las reinvidicaciones laborales colectivas de trabajadoras/es chilenos, son otra expresión más de la subalternidad no solo hacia las/los patrones, sino también respecto a aquellos colectivos que podían serles aparentemente más próximos en términos de las desigualdades laborales. Esto supuso generar estrategias de resistencia distintas a las hegemónicas, como el empoderamiento individual, el apoyo familiar y colectivo mapuche. Beatríz de 48 años (Santiago) habla de su madre:

Se ve a sí misma más empoderada, como que creció como mujer, que ha aprendido, que $i s i$ antes, era un pajarito!, ahora ¡ya no!, ya no va a aguantar lo que le hacían los patrones antes, o lo que le decía el patrón, ¡no, ahora ya no!, ella es capaz de pararse de otra forma frente al mundo, más segura.

El apoyo familiar en contextos de discriminación ha resultado central para forjar resistencias en las relaciones de opresión. Marcelina (66 años, Región de La Araucanía):

Entonces, cuando venía acá, a pasear, les contaba a ellos, me decían ¿y cómo le fue?, mi papá, mi mamá. 'Miren, a mí me tratan así, cuando estudiaba igual, me decían que yo hablaba feo, que yo hablaba así, que yo tenía que aprender a estudiar'. La monja me decía así. 'Yo no quiero ir a estudiar', yo lloraba por las noches. Y mi papá me decía 'usted no tiene que hacerle caso hija, usted tiene que estudiar no más, así va a ir aprendiendo, y después con el tiempo, usted se va a sentir orgullosa, ique usted va a saber varios idiomas poh!.

\section{Revitalización identitaria y lingüística mapuche en la ciudad y el Wallmapu}

Otra forma de micro-resistencia es la propia epistemología mapuche. Figuras como el profesor mapuche de Marcelina (66 años, Región de Los Ríos), contribuyeron a estos posicionamientos:

Decía 'nosotros somos distintos a estos winkas, ¡tú tenís que salir adelante!', me decía. Y yo me sacaba los siete, en francés, y yo hablaba con él en mapuche los dos no más, delante de todos los otros. Y ellos 'jajaja' 'no le hagai [hagas] caso, son todos malos del longko ${ }^{27}$.

La ciudad ha sido un espacio del cual las familias mapuche intentaron apropiarse simbólicamente. Graciela (43 años, Región de La Araucanía) nos dice:

Vivíamos en una casa grande, donde siempre estaba lleno ¿ya? siempre llegaban primos, tíos del campo, mi abuelita que llegaba y mi papá trataba de replicar un poco lo que él vivía acá poh! Por ejemplo, tenían huerta, mi mamá tenía gallinas, había un fogón atrás de la casa tipo... tipo ruka, donde ellos hacían las tortillas.

La apropiación de los espacios en la ciudad no fueron las únicas estrategias de micro-resistencia. La idea de la mujer "fuerte" fue otra manera de construir agencia. Adriana (35 años, Santiago) lo explica:

Es algo así como interno así, como también por lo que uno ve poh!, de las otras lamgenes, de... que han trabajado en trabajos súper difíciles y aun así han criado a sus hijos, han resistido tantas cosas y tanta opresión, que uno dice a veces 'porque le duelen los pies o le duele algo uno se va a echar a, se va a desvanecer o, o va a dejar de luchar' y no es así poh! Entonces como que uno se va dando esa fuerza.

Afrontar los desgarros de forma cotidiana implica construirse como una persona fuerte para habitar la ciudad, que segrega, clasifica y estigmatiza a 
diferentes colectivos humanos. Ahora, no todas las personas mapuche permanecen en la ciudad. En el retorno al Wallmapu surge un nuevo encuentro con el ser che, persona mapuche, la lengua propia, el mapudungun. Isolina (32 años, Región de La Araucanía), rompiendo con la violencia simbólica chilena y su internalización, afirma:

Y en realidad, 'ahí, nos dimos cuenta, de que no era tan malo ser mapuche', porque en Santiago, yo creo, nos hicieron sentir que era malo. Y después cuando volvimos, eh, fue como positivo, todo eso. Y, de hecho, mis papás volvieron a hablar mapudungun, porque ellos hablaban, pero en Santiago no hablaban. Y ahí, volvieron a hablar mapudungun en el campo, ¡eh!, y nosotros a aprender también.

En este proceso de resistencia y reapropiación, hablar mapudungun en un lof resulta una necesidad para re-encontrarse aunque sea a través de la diferencia con el pasado, como lo refiere Mariela (23 años, Región del Bíobio):

Mi abuelita siempre me estaba diciendo 'tenís que saber porque después más grande te van a preguntar [personas mapuche hablantes de la lengua, el mapudungun], y tú no vai a saber'. ¡Y así pasó po!, porque de repente me preguntan, me hablan en mapuche, yo no entiendo mucho, porque yo digo “¿qué me diría?” y ahí yo digo "sí poh!, mi abuelita tenía razón".

\section{Discusión y Conclusiones}

Las experiencias diaspóricas en contextos coloniales y patriarcales generó desgarros múltiples de clase, género y raza en las mujeres mapuche. El trabajo doméstico propició una pluralidad de opresiones al modo de apropiación colonial de las corporalidades femeninas mapuche (Bello 2002; Cumes 2014; Nahuelpan 2013) en las casas que servían. El silencio en las primeras épocas del despojo colonial sobre la situación de las mujeres mapuche muestra el escaso valor que se les ha dado como actoras políticas (Calfío 2019; Levil 2015; Montecino 1984). Pero, a su vez y de forma dialéctica, éstas han generado micro-resistencias en los espacios cotidianos. Han dado valor a su mapuchidad en la diáspora, y el retorno al Wallmapu, resistiendo a los procesos de opresión, reconstruyendo su ser mapuche en la diáspora en intersección con ser mujeres, ser trabajadoras y autónomas. Una forma de resistir ha sido revitalizar su mapuche kimün, sus prácticas propias, el mapudungun, su lengua, y el reymagnen como un sentido de colectividad en tanto pueblo y género. Otra forma es la identificación como mujer mapuche, como acto reivindicativo identitario (Huenchuñir 2015; Levil 2015) que desafía al capitalismo colonial y patriarcal, ya que se trata de un colectivo oprimido, y donde querer ser parte del mismo es una respuesta reivindicativa frente a las estructuras sociales que las vulneran.

La salida del lof estuvo condicionada por situaciones de precariedad material y por necesidad de cuidado de sí mismas y de sus familias, pero comporta también duelos constructivos. Las experiencias de explotación laboral en contextos de vulnerabilización se manifestaron en excesivas horas de trabajo, el no respeto a los horarios de descanso y comida, bajos salarios, entre otros abusos, pero a las que se pudieron poner ciertos límites. Las prácticas discursivas coloniales, específicamente la morenidad, el uso de la lengua o la vestimenta de las mujeres mapuche como símbolos de fealdad, de poco valor en el paradigma de la blanquitud y el desarrollismo. La construcción de su lugar como sirvientas, las enfrentó a prejuicios, estereotipos y discriminación racial, de clase y de género, en el espacio social y laboral que tuvieron que afrontar.

La fijación, para las mujeres mapuche, de lugares en el trabajo doméstico, feminizado, racializado e invisibilizado ha favorecido su deslegitimación social, y su invisibilidad. La diversidad de opresiones a nivel historiográfico y geográfico que las actoras de este estudio han afrontado, muestra que sus interseccionalidades son diferentes a la de los hombres mapuche y a las de las mujeres chilenas, pero también entre ellas mismas por motivos generacionales, entre otros.

Los estudios etnográficos sobre el pueblo mapuche y otros pueblos originarios, en escasas ocasiones se focalizan en la capacidad de agencia de las mujeres, al considerar a los hombres como representantes del pueblo mapuche. Hay distintas razones para ello. Una es que buena parte de estos estudios han sido realizados por varones -la mayoría- desde una perspectiva androcéntrica y sin detenerse en las mujeres como actoras. Otra razón remite a las dificultades de acceso a sus voces en el trabajo de campo (Hirsch 2008). Visibilizar las agencias cotidianas de las mujeres mapuche es un imperativo para generar propuestas políticas transformadoras.

Para resistir cotidianamente las actoras han reivindicado un conocimiento propio, el 'mapuche kimün', el cual involucra narrativas y prácticas que las conecta emocional y espiritualmente, y revitaliza el sentido de hermandad (sororidad), reymagnen. Los nütram, y valores mapuche enseñados por sus padres y madres, o personas mayores, son recordados en la diáspora, y en el retorno a Wallmapu. Estos saberes han sido tensionados por instituciones externas, como es el caso de otras religiones, que transforman prácticas y creencias pero que a la vez han posibilitado el afrontamiento de 
malestares internos, como el alcoholismo y la violencia de género.

La revitalización del mapuche kimün, la práctica de la lengua mapuche, el mapudungun, el principio del reymagnen, tanto en los espacios de la ciudad como en los lof en el Wallmapu, son formas de micro-resistencia a un proyecto colonial y neoliberal; persistiendo así una epistemología propia. Esto ha sido invisibilizado en diferentes espacios institucionales, pero algunas veces también por los propios hombres mapuche en el espacio académico y en las luchas políticas.

Este trabajo es un esfuerzo por romper el silencio respecto a las interseccionalidades de clase, raza y género y las micro-resistencias cotidianas de las mujeres mapuche que precisamos reconocer en diversos ámbitos sociales, políticos y académicos. Microresistencias entre despojos coloniales, que dan cuenta de configuraciones de 'identidades diaspóricas mapuche' emergentes en espacios cotidianos de mujeres mapuche, que han sido hasta ahora silenciadas, y que ponen en cuestión una supuesta identidad mapuche fija e identíca a sí misma, para permitir florecer una pluralidad de identidades mapuche ligadas a la experiencia de la diáspora.

Agradecimientos: La primera autora agradece a CONICYT, Chile, por la concesión de la Beca de Doctorado en el Extranjero del Programa de Formación de Capital Humano Avanzado, a las actoras del estudio, al equipo LAICOS IAPSE, los grupos de investigación Lis - Estudios sociales y de género sobre la corporalidad, la subjetividad y el sufrimiento evitable y Des-Subjectant (Grup d'Estudis Socials de la Subjecció i la Subjectivitat des d'una Perspectiva de Gènere Intersecciona) de la Universidad Autónoma de Barcelona, a la Dra. Mónica Martínez Mauri de la Universidad de Barcelona, al Dr. Dau García Dauder de la Universidad Rey Juan Carlos de Madridy alaDra. EsmeraldaCovarrubias de laUniversidad Autónoma Metropolitana de México. Finalmente, también queremos agradecer a las personas que han evaluado el manuscrito por sus valiosas sugerencias y aportes para mejorar este trabajo.

\section{Referencias Citadas}

Abarca, G. 2002. Mapuches de Santiago. Rupturas y continuidades en la recreación de la cultura. Revista de la Academia 7:105-120.

Alarcón, A.M. yY. Nahuelcheo 2008. Creencias sobre el embarazo, parto y puerperio en la mujer mapuche: Conversaciones privadas. Chungara Revista de Antropología Chilena 40 (2):193-202.

Alvarado, C. 2016. Silencios coloniales, silencios micropolíticos. Memorias de violencias y dignidades mapuche en Santiago de Chile. Aletheia 6 (12):1-17.

Alvarado, C. 2017. ¿Qué pueden temer los winka si los mapuche nos unimos? Raza, clase y lucha sindical mapuche. Santiago, 1925-1980. CUHSO 27 (2):121-151.

Ancán, J. y M. Calfío 1998. El retorno al país mapuche. Liwen 5:43-59.

Bello, Á. 2002. Migración, identidad y comunidad mapuche en Chile: entre utopismos y realidades. Asuntos Indígenas 3 (4):40-47.

Boccara, G. 2007. Los Vencedores. Historia del Pueblo Mapuche en la Época Colonial. Traducido por D. Milos. Línea Editorial IIAM. Universidad Católica del Norte, Antofagasta.

Braun, V. y V. Clarke 2008. Using thematic analysis in psychology. Qualitative Research in Psychology 3 (2):77-101.

Cáceres, P. 2003. Análisis cualitativo del contenido: una alternativa alcanzable. Psicoperspectivas II:53-82.

Calfío, M. 2012. Peküyen. En Ta iñ fijke xipa rakizuameluwün. Historia, Colonialismo y Resistencia desde el País Mapuche, editado por H. Nahuelpan M., H. Huinca P. y P. Mariman, pp. 279-296. Ediciones Comunidad de Historia Mapuche, Temuco.

Calfío, M. 2019. Yafüluwayiñ mapucheke pu zomo. Mongelechi newentun siglos XIX ka XX. Yafluayiñ, mujeres mapuche. Resistencia viva en los siglos XIX y XX. En ¡Allkütunge, wingka! jka kiñechi!. Ensayos sobre Historias Mapuche, editado por P. Marimán, F. Nahuelquir, J. Millalén, M. Calfío y R. Levil, pp. 235-270. Ediciones Comunidad de Historia Mapuche, Temuco.

Caniuqueo, S. 2009. Particularidades en la instauración del colonialismo chileno en el Gulu Mapu, 1884-1950. Subordinación, alianzas y complicidades. En Las Disputas por la Etnicidad en América Latina: Movilizaciones Indígenas en Chipas y Araucanía, editado por C. Martínez y M. Estrada, pp. 191-212. Catalonia, Santiago.

Cho, S., K. Crenshaw y L. McCall 2013. Toward a field of intersectionality studies: Theory, applications, and praxis. Signs 38 (4):785-810.

Combahee River Collective 2012 [1977]. Un manifiesto feminista negro. En Intersecciones: Cuerpos y Sexualidades en la Encrucijada, editado por L. Platero, pp. 75-86. Ediciones Bellaterra, Barcelona.

Comisión Económica para América Latina y el Caribe [CEPAL] Censo 2017. Base de Datos de población. Centro Latinoamericano y Caribeño de Demografía [CELADE]. División de Población de la Comisión Económica para América Latina y el Caribe [CEPAL] 2019. Datos procesados con Redatam WebServer. (24 octubre). https://redatam-ine.ine.cl/redbin/RpWebEngine.exe/ Portal?BASE=CENSO_2017\&lang=esp

Cumes, A. 2009. "Sufrimos vergüenza": Mujeres K'iche frente a la justicia comunitaria en Guatemala. Desacatos 31:99-114.

Cumes, A. 2014. La "India" como "Sirvienta": Servidumbre Doméstica, Colonialismo y Patriarcado en Guatemala. Tesis para optar al grado de Doctora en Antropología, Centro de Investigaciones y Estudios Superiores en Antropología Social, México D.F.

Curivil, F. 2006. Asociatividad Mapuche en el Espacio Urbano. Santiago 1940-1970. Informe final de Seminario de Grado para obtener el grado de Licenciado en Historia, Departamento de Ciencias Históricas, Universidad de Chile, Santiago.

Curiel, O. 2007. Crítica poscolonial desde las prácticas políticas del feminismo antiracista. Revista Nómadas 26:92-101.

Clifford, J. 1999. Itinerarios Transculturales. Editorial Gedisa, Barcelona.

Díaz, C. 2005. Aproximaciones al arraigo y desarraigo femenino en el medio rural: Mujeres jóvenes en busca de una nueva identidad rural. Papers 75:63-84. 
Espinosa, Y. 2009. Etnocentrismo y colonialidad en los feminismos latinoamericanos: Complicidades y consolidación de las hegemonías feministas en el espacio transnacional Revista venezolana de Estudios de la Mujer 14 (33):37-54.

Guerra, L. 2014. La Ciudad Ajena: Subjetividades de Origen Mapuche en el Espacio Urbano. Segunda edición, Ediciones Ceibo, Santiago.

Gündermann, H., H. González y L. De Ruyt 2009. Migración y movilidad mapuche a la Patagonia Argentina. Magallania 37 (1):21-35.

Hall, S. 2003. Introducción: ¿quién necesita “identidad”? En Cuestiones de Identidad Cultural, editado por S. Hall y P. du Gay, pp. 13-39. Amorrortu editores, Buenos Aires.

Hernández, I. 2003. Autonomía o Ciudadanía Incompleta. El Pueblo Mapuche en Chile y Argentina. Pehuén/CEPAL, Santiago.

Hirsch, S. 2008. La mujer indígena en la antropología argentina: una breve reseña. En Mujeres Indígenas en la Argentina. Cuerpo Trabajo y Poder, compilado por S. Hirsch, pp. 15-26. Biblos, Buenos Aires.

Huenchuñir, S. 2015. Exilio interior, ser mapuche en Santiago. En Rupturas e identidades. Cuestionando la Nación y la Academia desde la Etnia y el Género, editado por A. Boitano y A. Ramm, pp. 45-65. RIL editores, Santiago.

Imilan, W. 2014. La experiencia warriache, espacios, performances e identidades mapuche en Santiago. En Poblaciones en Movimiento. Etnificación de la Ciudad, Redes e Integración, editado por W. Imilan, A. Garcés y D. Margarit, pp. 254-278. Ediciones Universidad Alberto Hurtado, Santiago.

Instituto Nacional de Estadística [INE] 2017. Censo 2017. (17 octubre). https://www.censo2017.cl/descargas/home/sintesisde-resultados-censo2017.pdf

Levil, X. 2015. Reflexiones y relatos de una mujer mapuche. En Rupturas e Identidades. Cuestionando la Nación y la Academia desde la Etnia y el Género, editado por A. Boitano y A. Ramm, pp. 29-44. RIL editores, Santiago.

McCall, L. 2005. The complexity of intersectionality. Signs 30 (3):1771-1800

Mallon, F. 2009. El siglo XX mapuche: esferas públicas, sueños de autodeterminación y articulación internacionales. En Las Disputas por la Etnicidad en América Latina: Movilizaciones Indígenas en Chiapas y Araucanía, editado por C. Martínez y M. Estrada, pp. 155-191. Ediciones Catalonia, Santiago.

Mariman, P. 2006. Los mapuche antes de la conquista militar chileno-argentina. En i... Escucha Winka...! Cuatro Ensayos de Historia Nacional Mapuche y un Epílogo sobre el Futuro, editado por P. Marimán, S. Caniuqueo, J. Millalen y R. Levil, pp. 53-127. Ediciones LOM, Santiago.

Millaleo, A. 2011. Ser 'Nana' en Chile: Un Imaginario Cruzado por Género e Identidad Étnica. Tesis para optar al grado de
Magíster en Estudios de Género, Mención Ciencias Sociales, Centro Interdisciplinario de Estudios de Género, Universidad de Chile, Santiago.

Ministerio de Desarrollo Social. Encuesta de Caracterización Socioeconómica [CASEN] 2015. (22 octubre). http://observatorio. ministeriodesarrollosocial.gob.cl/casen-multidimensional/casen/ docs/CASEN_2015_Resultados_pueblos_indigenas.pdf

Montecino, S. 1986. Mujeres de la Tierra. Ediciones CEMPemci, Santiago.

Mora, E. y J. León 2011. La globalización del cuidado y sus cadenas: Un estudio de caso. Psicoperspectivas 10 (2):109-133.

Nahuelpán, H. 2013. Las "zonas grises" de las historias mapuche. Colonialismo internalizado, marginalidad y políticas de la memoria. Revista de Historia Social y de las Mentalidades 17 (1):11-33

Nahuelpán, H. 2012. Formación colonial delEstado y desposesión en Ngulu Mapu. En Ta iñ fijke xipa rakizuameluwün. Historia, Colonialismo y Resistencia desde el País Mapuche, editado por H. Nahuelpán, H. Huinca y P. Marimán, pp. 123-156. Ediciones Comunidad de Historia Mapuche, Temuco.

Ríos, M. y J.L. Solís 2009. Etnodesarrollo: reivindicación del "indio mexicano" entre el discurso del Estado y el discurso desarrollista. Cuadernos interculturales 7 (13):180-205.

Rivera, S. 2010. Ch'ixinakax utxiwa. Una Reflexión sobre Prácticas y Discursos Descolonizadores. Editorial Tinta Limón, Buenos Aires.

Rojo Salomone, A. y C. Zapata 2003. Postcolonialidad y Nación Ediciones LOM, Santiago.

Segato, R. 2018. Manifiesto en cuatro temas. Critical Times 1:212 225

Sepúlveda, B. y P. Zúñiga 2015. Geografías indígenas urbanas: el caso mapuche en la Pintana, Santiago de Chile. Revista de Geografía Norte Grande 62:127-149.

Stolcke, V. 1993. Mujeres invadidas. La sangre de la conquista de América. En Mujeres Invadidas. La Sangre de la Conquista de América, editado por V. Stolcke, pp. 29-46. Ediciones Grijalbo, México D.F.

Tuhiwai, L. 2016 [1999]. A Descolonizar las Metodologías. Investigación y Pueblos Indígenas. Traducido por Kathryn Lehman. Ediciones LOM, Santiago.

Yuval-Davis, N. 2006. Intersectionality and feminist politics. European Journal of Women's Studies 13 (3):193-209.

Yuval-Davis, N. 2017. Situated Intersectionality and the Meanings of Culture. Consello da Cultura Galega, Galicia.

Zavala, J.M. 2008. Los Mapuche del Siglo XVIII. Dinámica Interétnica y Estrategias de Resistencia. Traducido por C.G. Garbarini. Ediciones Universidad Bolivariana, Santiago.
${ }^{1}$ Cuando hablamos de Wallmapu nos referimos al territorio histórico mapuche establecido como acuerdo político para autordeterminación territorial del pueblo mapuche con la Corona Española en el Parlamento de Quilín en 1641. Este estableció una línea fronteriza al sur del Bíobio como territorio mapuche, y hacia el norte como territorio español.
${ }^{2}$ La Universidad Autónoma de Barcelona promueve como uso obligado en las investigaciones sociales seguir los lineamientos del "código de buenas prácticas". Ver en: http:// www.recerca.uab.es/ceeah/docs/CBPC-cat.pdf.

${ }^{3}$ Una de las autoras del artículo, forma parte del pueblo mapuche, por lo que conoce y comparte dichos códigos, y realizó el trabajo 
de campo etnográfico. Las definiciones de los conceptos mapuche las realizó desde un conocimiento colectivo aprendido con sus familiares, personas de su lof, y de lo que con otras personas con mayor conocimiento ha venido aprendiendo en su trayectoria vital en diferentes espacios.

4 Pentukün trata de convenciones sociales propias mapuche, entre dos o más personas, cuyo propósito es el de afianzar confianzas, conocerse, establecer acuerdos en la relación y cuidar la misma en el transcurso del tiempo.

5 Küpal, involucra el conocimiento que se traspasa generacionalmente, y de forma oral, principalmente, al interior de las familias mapuche respecto a su historia en cuanto a linaje, las características de la familia, sus logros, cargos y la trayectoria que la define. Trata de las raíces.

${ }^{6}$ Tüwün al igual que el küpal, conforman elementos centrales para la identificación como persona mapuche. Remite a la historia del territorio en el cual las personas mapuche interactúan con los ngen, que son los cuidadores o dueños, por ejemplo del mar, de las montañas. Entonces la relación es de respeto con estos ngen, y la construcción de la historia de un lof no se comprende sin dicha interacción. De este modo, han surgido definiciones sobre el ser lafkenche, -persona del mar-, por la estrecha relación con el mar, las prácticas ceremoniales asociadas a este, el tipo de alimentación y los diversos sistemas de creencias giran en torno a esta relación.

${ }^{7}$ Lof refiere a la conformación de un colectivo de familias en un determinado espacio territorial. Se compone de tres o más troncos familiares, que comparten historias propias, prácticas, creencias y usos y significados del mapudungun.

${ }^{8}$ Los despojos de tierras sufridos por el pueblo mapuche tuvo como una de sus estrategias, la firma de documentos engañosos que implicaron robos de tierras, de parte de colonos o chilenos. Por respeto, no quisimos rememorar estos traumas históricos.

${ }^{9}$ Usamos la terminología mapuche como reconocimiento del saber propio de las mujeres y el de todo un pueblo. No haremos una traducción literal, ya que, dependiendo de cada lof, de cada territorio (sumado el respeto a personas mapuche hablantes y/o lingüistas especializadas). No obstante, presentamos elementos generales, sobre los que hay consenso, a fin de lograr comprender el contexto de estas terminologías y su sentido colectivo.

${ }^{10}$ Kimün involucra conocimiento sobre las prácticas, creencias y la lengua mapuche. Dicho conocimiento también puede ser reconocido sobre otras materias u oficios. Por ejemplo, una persona que tiene conocimiento y práctica en la orfebrería, en el trabajo con la plata para elaborar joyas, las personas que saben tejer a telar, entre otras.

${ }^{11}$ Nütram comprende consejos otorgados por personas mayores, o que tienen mayor conocimiento que aportar, lo cual orienta la vida, las prácticas y costumbres de las personas mapuche. Es un consejo de vida, para ser che, persona que sigue los principios valóricos mapuche, los cuales ya hemos descrito en otra nota.

${ }^{12} \mathrm{El}$ che refiere a la formación de persona asociada a ciertos valores. Estos son el ser un kümeche, es decir buena persona; ser norche, persona recta, que sigue las normas de respeto establecidas en un lof; ser un lifche, persona de corazón limpio, que no alberga sentimientos negativos hacia otras personas; ser un kimche, un valor que es posible de alcanzar a una edad avanzada, o bien por el reconocimiento que las personas de su lof hacen para caracterizarle como kimche, por la sabiduría que ésta tiene sobre determinadas materias, especialmente conocimiento sobre prácticas, lengua mapuche o memoria histórica.

${ }^{13}$ Winka es un concepto con el cual el pueblo mapuche ha denominado a las personas occidentales. Algunas personas mapuche refieren que este concepto fue creado para hablar de personas españolas que una vez llegados a territorio mapuche, fueron categorizados como otro Inka, que fue el primer imperio que intentó conquistar al pueblo mapuche. La traducción allí sería 'otro Inka'.

${ }^{14}$ Mapudungun es la lengua propia del pueblo mapuche. Antes del avance español hacia el territorio mapuche, por medio de la conquista, esta lengua en el siglo XVIII ocupó gran parte de las tierras fértiles de Chile, como lo refiere el antropólogo José Manuel Zavala (2008). La pronunciación, el ritmo y algunos significados difieren de acuerdo a la ubicación territorial. Así, el habla de personas lafkenche, no siempre coincide con el habla de los pewenche, personas que habitan la cordillera.

${ }^{15}$ Hemos usado nombres ficticios para resguardar el anonimato de las actoras del estudio.

${ }^{16} N$ gillatün es una ceremonia colectiva mapuche que se realiza de acuerdo a las prácticas propias de cada lof. Estas ceremonias pueden realizarse una vez al año, cada dos o cada cuatro años, dependiendo de las costumbres de cada territorio. Las razones son principalmente para agradecer por los frutos, las hortalizas, las cosechas y lo que se haya obtenido en el año. Así también se pide por la armonía, la salud y la posibilidad de contar con lo necesario para sobrevivir en los años que siguen, que la relación con la naturaleza y los espíritus, así como con las personas, se encuentren en equilibrio. En algunos territorios se realizan para afrontar plagas o bien por las afectaciones que acontecen por la violencia estatal colonial. Sus principios son el fortalecimiento de los vínculos afectivos entre quienes componen un lof, y en relación a otros lof.

${ }^{17}$ Lamuen es una forma de llamarse entre las mujeres, y de éstas a los hombres, significa ser hermanas/os. De acuerdo al lof, puede decirse también, lamgnen. Su significado es el mismo.

${ }^{18}$ Mingako es un concepto que se usa para denominar acciones de colaboración en trabajos de cosecha, siembra, entre otros, con sentido de reciprocidad. Se trata de acciones que pretenden mantener vínculos sociales y afectivos. Una persona o familia recibe apoyo de otras, y luego ellas lo devuelven cuando otras personas de su lof, o las que le ayudaron, lo necesitan.

${ }^{19}$ De acuerdo a la identificación mapuche en cuanto territorialidad, al ngillatün se le llama trawün. En otros espacios, los trawün remiten a reuniones ampliadas para tratar temas que aquejan a los lof, familias en particular, o al pueblo mapuche en general.

${ }^{20}$ Machitucarse refiere a la acción que realiza una o un machi, persona con sabiduría sobre espiritualidad y conocimiento de las hierbas medicinales. Su acción es para alcanzar el equilibrio, el cual se ha perdido, ya sea por razones de enfermedades físicas, psíquicas o espirituales.

${ }^{21}$ Ngen son los espíritus protectores o dueños de un espacio físico, el cual puede estar en el mar, en la montaña o en un espacio específico en la tierra u otros elementos de la naturaleza. La costumbre mapuche es respetar esos espacios, pedir permiso para estar en ellos, entre otras acciones. Se trata de una coexistencia mutua.

${ }^{22}$ Chaw Ngenechen es una forma de denominar a un espíritu protector, al cual las personas mapuche se dirigen en las ceremonias. No es similar al concepto de Dios, como se podría relacionar con la creencia Judeo-Cristiana, tiene cualidades y significados propios. Así como existe el concepto de la ñuke mapu, referido a la madre tierra. Ambos espíritus son respetados y nombrados para pedir permiso, para pedir apoyo y fuerza.

${ }^{23}$ Reymagnen es una forma de conceptualizar los vínculos de hermandad en cuanto al apoyo social, a las expresiones de cariño y el sentido de pueblo. Esto se expresa en la relación que se establece entre dos o más personas mapuche.

${ }^{24}$ Muchai bebida a base de trigo y agua cocida, que se deja fermentar por dos semanas en barriles de madera. Su uso es principalmente ceremonial. Se entrega como forma de expresión de cariño a las personas que participan de un ngillatün $\mathrm{u}$ otra ceremonia mapuche. Su sabor es suave, parecido al jugo -zumo- de coco. En algunos lugares se le llama también mudai.

${ }^{25} \tilde{N}$ gol se refiere al espacio ceremonial central que se genera en un ngillatün.

${ }^{26}$ Zugu Machife es una persona de confianza del o la machi, que le acompaña física y espiritualmente en sus labores de sanación. Tiene un conocimiento y un linaje que le permiten ocupar este rol. 
${ }^{27}$ Longko es un concepto que se utiliza para denominar a las personas que tienen como cargo la organización y funcionamiento sociopolítico de un lof. Así mismo, se le llama a la cabeza del cuerpo, en este caso el humano. 